\title{
Does a mobile laminar airflow screen reduce bacterial contamination in the operating room? A numerical study using computational fluid dynamics technique
}

\author{
Sasan Sadrizadeh ${ }^{1 *}$, Ann Tammelin ${ }^{2}$, Peter V Nielsen ${ }^{3}$ and Sture Holmberg ${ }^{1}$
}

\begin{abstract}
Background: Air-borne bacteria in the operating room (OR) may contaminate the surgical wound, either by direct sedimentation from the air or indirectly, by contaminated sterile instruments. Reduced air contamination can be achieved with an efficient ventilation system. The current study assesses the additive effect of a mobile laminar airflow (MLAF) unit on the microbiological air quality in an OR supplied with turbulent-mixing air ventilation.

Methods: A recently designed OR in NKS (Nya Karolinska Sjukhuset, Stockholm, Sweden) was the physical model for this study. Simulation was made with MLAF units adjacent to the operating table and the instrument tables, in addition to conventional turbulent-mixing ventilation. The evaluation used numerical calculation by computational fluid dynamics (CFD). Sedimentation rates (CFU/ $\mathrm{m}^{2} / \mathrm{h}$ ) were calculated above the operating table and two instrument tables, and in the periphery of the OR. Bacterial air contamination $\left(\mathrm{CFU} / \mathrm{m}^{3}\right)$ was simulated above the surgical and instrument tables with and without the MLAF unit.

Results: The counts of airborne and sedimenting, bacteria-carrying particles downstream of the surgical team were reduced to an acceptable level for orthopedic/implant surgery when the MLAF units were added to conventional $O R$ ventilation. No significant differences in mean sedimentation rates were found in the periphery of the OR.

Conclusions: The MLAF screen unit can be a suitable option when the main OR ventilation system is unable to reduce the level of microbial contamination to an acceptable level for orthopedic implant surgery. However, MLAF effect is limited to an area within $1 \mathrm{~m}$ from the screen. Increasing air velocity from the MLAF above $0.4 \mathrm{~m} / \mathrm{s}$ does not increase the impact area.
\end{abstract}

Keywords: Air-borne bacteria, Colony-forming unit, Operating room, Microbiological air quality, Mobile ultraclean exponential laminar airflow screen, CFD simulation

\section{Background}

Surgical site infections, air-borne transmission and ventilation

Surgical-site infections (SSIs) are serious and contribute to higher rates of patient morbidity and mortality, increased hospitalization time, and patient dissatisfaction [1]. Infections after hip- and knee-prosthetic surgery are

\footnotetext{
* Correspondence: sasan.sadrizadeh@byv.kth.se

'Division of Fluid and Climate Technology, School of Architecture and the Built Environment, KTH Royal Institute of Technology, Stockholm, Sweden
} Full list of author information is available at the end of the article devastating. Several measures must be taken to reduce the infection rate [2].

It is well-known that operating room (OR) personnel are the main source of airborne bacteria as they disseminate infectious particles into their surrounding environment. A person releases about $10^{4}$ skin scales per minute during walking, 10 percent of which carry bacteria [3]. However, the count of discharged microorganisms varies widely, even as much as 12-fold, between individuals and sampling days [4]. The size of the particles carrying microorganisms has been reported ranging from 4-60 $\mu \mathrm{m}[5,6]$. Bacteria suspended in the OR air may contaminate the

C Biomed Central

Sacher

(c) 2014 Sadrizadeh et al.; licensee BioMed Central Ltd. This is an Open Access article distributed under the terms of the Creative Commons Attribution License (http://creativecommons.org/licenses/by/4.0), which permits unrestricted use, distribution, and reproduction in any medium, provided the original work is properly credited. The Creative Commons Public Domain Dedication waiver (http://creativecommons.org/publicdomain/zero/1.0/) applies to the data made available in this article, unless otherwise stated. 
surgical wound, either by direct sedimentation from the air or indirectly by contaminated surgical instruments [7].

Air contamination can be reduced with an efficient ventilation system to dilute and evacuate contaminants from the OR [8], increasing the performance of staff clothing to prevent bacteria shedding to the air [9], and restricting the number of people and their activity in the OR $[10,11]$.

Laminar airflow (LAF) is the most efficient OR ventilation system $[8,12]$. However, indoor obstacles including medical lamps, surgical staff, and equipment can easily affect the unidirectional airflow pattern of a vertical LAF system [13,14]. Intended colony-forming unit (CFU) levels $\left(<10 \mathrm{CFU} / \mathrm{m}^{3}\right)$ will not be present, and the desired SSI-rate decrease cannot be achieved. Installing a LAF ventilation system might also be difficult in existing ORs and is costly when constructing new ORs. A mobile laminar airflow (MLAF) unit could overcome both the problem with physical obstacles and costs.

A MLAF unit with conventional turbulent-mixing ventilation is a valuable complement to general ventilation in reducing bacterial load during operations in an OR [15-19]. The authors conclude that the additional MLAF screen reduced the number of viable airborne bacteria and sedimenting, bacteria-carrying particles (BCPs) to the same level as ultra-clean LAF-ventilation.

\section{Microbiological air-sampling methods}

Currently, microbiological air sampling in ORs is performed either by passive air sampling (PAS) with settle plates or by active air sampling (AAS) with a slit sampler, impaction sampler, or filter sampler [20]. PAS measures the settlement rate of viable particles on surfaces, while AAS provides information about the concentration of viable particles in the air. Both methods require access to a bacteriological laboratory and can only be used in existing ORs. Sadrizadeh et al. provides a more detailed explanation of the mathematical modeling of active and air-sampling methods [10].

\section{Computational fluid dynamics}

It is important to control air distribution in enclosed spaces to create and maintain a comfortable, healthy atmosphere for occupants, especially in sensitive indoor environments such as ORs. Experimental studies provide direct evidence of airflow and particle-transport phenomena. However, the complexity of indoor airflow makes experimental investigation very difficult and expensive.

With recent advances in computer technology in various methods, computational fluid dynamics (CFD) has become an essential complementary tool to physical experiments. CFD is the science of predicting fluid or gas flow, which largely reduces the number of required physical experiments and provide great potential for improving prediction accuracy of air distribution in enclosed environments. This method was successfully applied in simulated OR environments [10,13,21]. The data made it possible to clarify uncertainties at initial stages of design. Obtaining precise information can provide an important foundation on which to base design decisions. It can also overcome some measurement limitations and extend the range of research. Generally, the CFD technique has three main steps.

Pre-processing: This step consists of defining simulation domain and grid generation. The domain in which flow is to be analyzed requires modeling, generally with a CAD software package. For the complex geometries, some degree of simplification may be required to correct the geometry and make it valid as a CFD model. Portions of the flow-domain boundary coincide with the surfaces of the body geometry. The spatial geometric spaces the fluid occupies are modeled so as to provide input for grid generation. Mesh generation is essential in the CFD analysis process, which subdivides the domain into discrete cells, known as grid or mesh. The created mesh surrounds the object and then extends in all directions to get the physical properties of the surrounding fluid; in other words, the OR air in the present study. The mesh is very fine in areas with large gradients in the flow field and coarser in regions with relatively little change.

Boundary condition and solve: Numerical simulation generally requires input parameters consisted of the desired strategy. The boundary conditions are specified as the fluid properties and behavior at the boundaries of the problem, inlet temperature and velocity, and particle generation rate. The numerical solution is obtained by an iterative method, which achieves high accuracy using a large number of repetitions. As the simulation proceeds, the solution is monitored to determine if a converged solution has been obtained.

Post-processing: This stage involves extracting the desired flow properties (velocity, particle concentration, temperature) from the computed flow field. This is accomplished by means of contour and color plots, vector plots, and animation for dynamic result.

Result sensitivity should be examined to understand possible differences in the accuracy of results and with respect to initial flow conditions and experimental investigation.

\section{Methods}

A newly designed NKS (Nya Karolinska Sjukhuset) OR, which was adopted in the authors' previous work, $[10,22]$ was chosen as the physical model for this study. The OR dimensions are L $8.5 \mathrm{~m} \times \mathrm{W} 7.7 \mathrm{~m} \times \mathrm{H} 3.2 \mathrm{~m}$. Figure 1 shows the geometrical configuration.

Ventilating air was introduced through 24 diffusers, evenly spaced over the ceiling, with a total airflow rate 


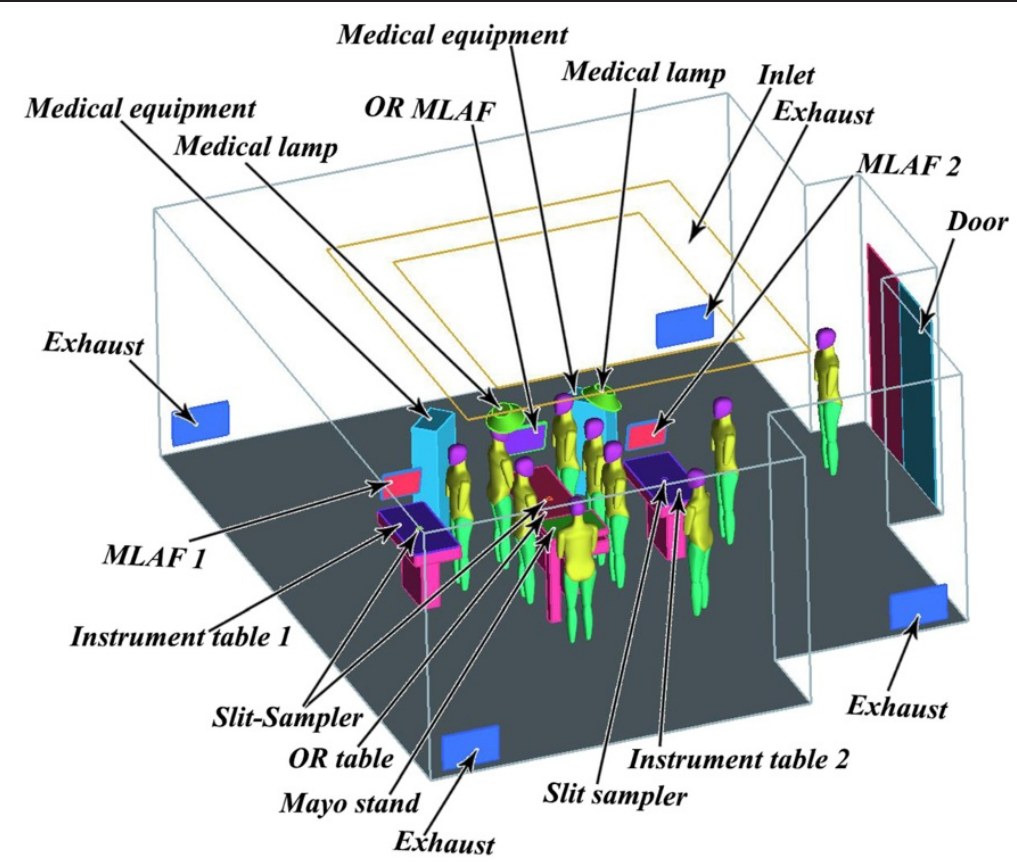

Figure 1 An isometric view of the OR model.

of $2500 \mathrm{~L} / \mathrm{s}$, yielding a design ventilation rate 47 air changes per hour $(\mathrm{ACH})$. Outgoing air was extracted through four exhaust openings placed on the parallel vertical walls at floor level. Ten surgical staff members were placed in upright stationary positions, mostly around the operating table. A MLAF (TOUL-400) screen was placed at the foot end of the operating table, with the air flow directed along the table. Two sterile instrument tables equipped with MLAFs (TOUL-300) were also considered. Figure 2 shows two MLAF units in an OR, one placed at the foot of the operating table and the other at the end of an instrument table. A source strength (mean value of CFUs emitted from one person per second) of five $\mathrm{CFU} / \mathrm{s}$ per individual was considered for each surgical staff

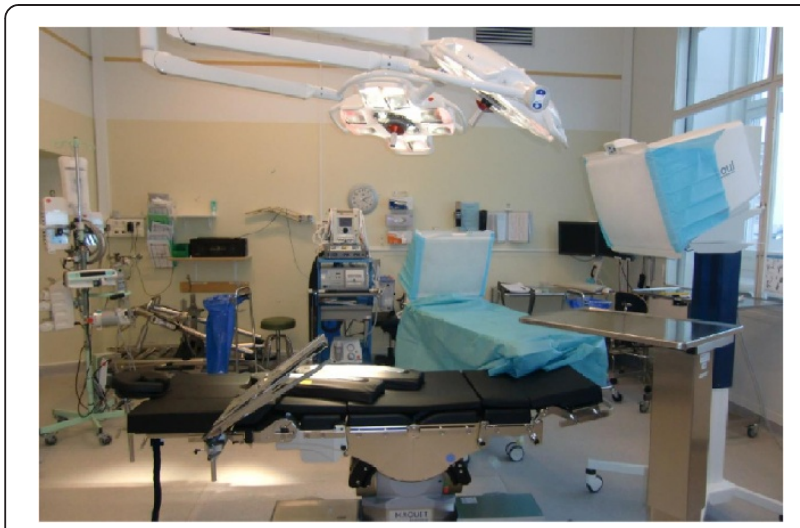

Figure 2 Two MLAF units in an OR. Photo from South Hospital (Södersjukhuset), Stockholm. member, in accordance with SIS-TS 2012 [23]. Simulation was performed under different MLAF centerline velocities from zero (MLAF unit switched off) to $1.0 \mathrm{~m} / \mathrm{s}$.

The authors performed a comprehensive validation of the flow field between numerical CFD results and measured data [10]. The relative error between measurement and simulation was less than 5 percent. However, this aspect was outside the scope of the present study and not analyzed here.

In this study, both AAS and PAS approaches were numerically simulated. The simulated AAS method estimated air at a total flow rate of $100 \mathrm{~L} / \mathrm{min}$, drawn for $10 \mathrm{~min}$ through a slit sampler installed above each table.

Table 1 Mean values of volumetric bacteria-carrying particles for different centerline velocity of the mobile laminar screen unit

\begin{tabular}{|c|c|c|c|}
\hline \multirow{2}{*}{$\begin{array}{l}\text { MLAF screen } \\
\text { velocity }\end{array}$} & Operating table & $\begin{array}{l}\text { Instrument } \\
\text { table one }\end{array}$ & $\begin{array}{l}\text { Instrument } \\
\text { table two }\end{array}$ \\
\hline & $\mathrm{CFU} / \mathrm{m}^{3}$ & $\mathrm{CFU} / \mathrm{m}^{3}$ & $\mathrm{CFU} / \mathrm{m}^{3}$ \\
\hline$(\mathrm{m} / \mathrm{s})$ & Mean (min-max) & Mean (min-max) & Mean (min-max) \\
\hline off & $19.08(9-32)$ & $18.12(13-28)$ & $7.66(5-24)$ \\
\hline 0.2 & $9.94(4-12)$ & $8.36(3-13)$ & $1.82(1-4)$ \\
\hline 0.4 & $1.21(1-4)$ & $1.14(0-5)$ & $0.90(0-3)$ \\
\hline 0.6 & $0.72(0-3)$ & $0.08(0-1)$ & $0.08(0-1)$ \\
\hline 0.8 & $0.04(0-1)$ & $0.06(0-1)$ & $0.00(0-0)$ \\
\hline 1.0 & $0.00(0-0)$ & $0.00(0-0)$ & $0.00(0-0)$ \\
\hline
\end{tabular}

CFD simulation results were based on active air-sampling method. (CFU: colony-forming unit, MLAF: mobile laminar airflow). 
Table 2 Mean values of sedimenting bacteria-carrying particles for different centerline velocities of the MLAF unit

\begin{tabular}{lcccr}
\hline $\begin{array}{l}\text { MLAF } \\
\text { screen } \\
\text { velocity } \\
\text { (m/s) }\end{array}$ & $\begin{array}{c}\text { Operating table } \\
\mathbf{C F U} / \mathbf{m}^{2} / \mathbf{h}\end{array}$ & $\begin{array}{c}\text { Instrument table one } \\
\mathbf{C F U} / \mathbf{m}^{2} / \mathbf{h}\end{array}$ & $\begin{array}{c}\text { Instrument table two } \\
\mathbf{C F U} / \mathbf{m}^{2} / \mathbf{h}\end{array}$ & $\begin{array}{c}\text { OR periphery } \\
\mathbf{C F U} / \mathbf{m}^{2} / \mathbf{h}\end{array}$ \\
\hline off & Mean (min-max) & Mean (min-max) & Mean (min-max) & Mean (min-max) \\
0.2 & $180.78(157-210)$ & $225.80(155-312)$ & $51.06(32-63)$ & $382.85(289-401)$ \\
0.4 & $43.94(34-55)$ & $96.44(83-121)$ & $27.86(23-35)$ & $380.36(254-421)$ \\
0.6 & $14.02(11-20)$ & $37.42(32-65)$ & $19.92(14-29)$ & $393.69(298-501)$ \\
0.8 & $15.84(8-19)$ & $29.54(21-52)$ & $18.80(15-24)$ & $390.50(301-423)$ \\
1.0 & $14.70(9-14)$ & $22.72(21-40)$ & $17.44(13-22)$ & $384.85(319-419)$ \\
\hline
\end{tabular}

CFD simulation results were based on the passive air-sampling method. (CFU: colony-forming unit, MLAF: mobile laminar airflow).

The total number of CFU was then counted, and the concentration presented as the number of $\mathrm{CFU} / \mathrm{m}^{3}$. This gave a direct quantitative estimate of the number of CFUs in the sampled air. In the simulated PAS approach, the total surface area of the tables were exposed to the OR air during one hour, and results were estimated as $\mathrm{CFU} / \mathrm{m}^{2} / \mathrm{h}$. For each case, air sampling was repeated 100 times to achieve statistically reliable results. Sadrizadeh et al. provide more details of numerical AAS and PAS calculations $[10,22]$.

\section{Results}

Table 1 shows the mean value of volumetric BCP concentration $\left(\mathrm{CFU} / \mathrm{m}^{3}\right)$ as a function of MLAF screen velocity obtained by CFD simulation of the AAS method. Mean concentration of BCPs in the air above the operating table was $19 \mathrm{CFU} / \mathrm{m}^{3}$ with standard OR ventilation. When the MLAF unit was functioning at a velocity of $0.4 \mathrm{~m} / \mathrm{s}, \mathrm{BCP}$ concentrations decreased to a mean value of $1 \mathrm{CFU} / \mathrm{m}^{3}$. The same BCP concentration trend was seen for instrument table one. The number of microorganisms in the air above instrument table two was lower with standard OR ventilation than for the other tables, due to the local airflow pattern and the distance of this table from the surgical team members. However, when the MLAF unit was functioning, the concentration of $8 \mathrm{CFU} / \mathrm{m}^{3}$ dropped to a concentration of $1 \mathrm{CFU} / \mathrm{m}^{3}$.

Table 2 shows the mean value of BCP sedimentation rate $\left(\mathrm{CFU} / \mathrm{m}^{2} / \mathrm{h}\right)$ above the tables and in the OR periphery, with and without a MLAF screen, when simulating the PAS method. When the main OR ventilation system functioned without a MLAF screen, the mean values of BCP sediment distribution on the surface area of the operating table, and instrument tables one and two, respectively were 180,225 , and $51 \mathrm{CFU} / \mathrm{m}^{2} / \mathrm{h}$. When the MLAF unit was at a velocity of $0.4 \mathrm{~m} / \mathrm{s}$, the sedimentation rates were reduced to values of 14,37 , and $19 \mathrm{CFU} / \mathrm{m}^{2} / \mathrm{h}$. There was no further reduction when the velocity increased from $0.4 \mathrm{~m} / \mathrm{s}$ to $1.0 \mathrm{~m} / \mathrm{s}$. No major difference in BCP sedimentation rate could be observed in the peripheral area of the OR, with or without MLAF units.

Figure 3 shows the impact area of MLAF units, as a function of screen velocity and the distance from the center point of the MLAF screen. The area impact of
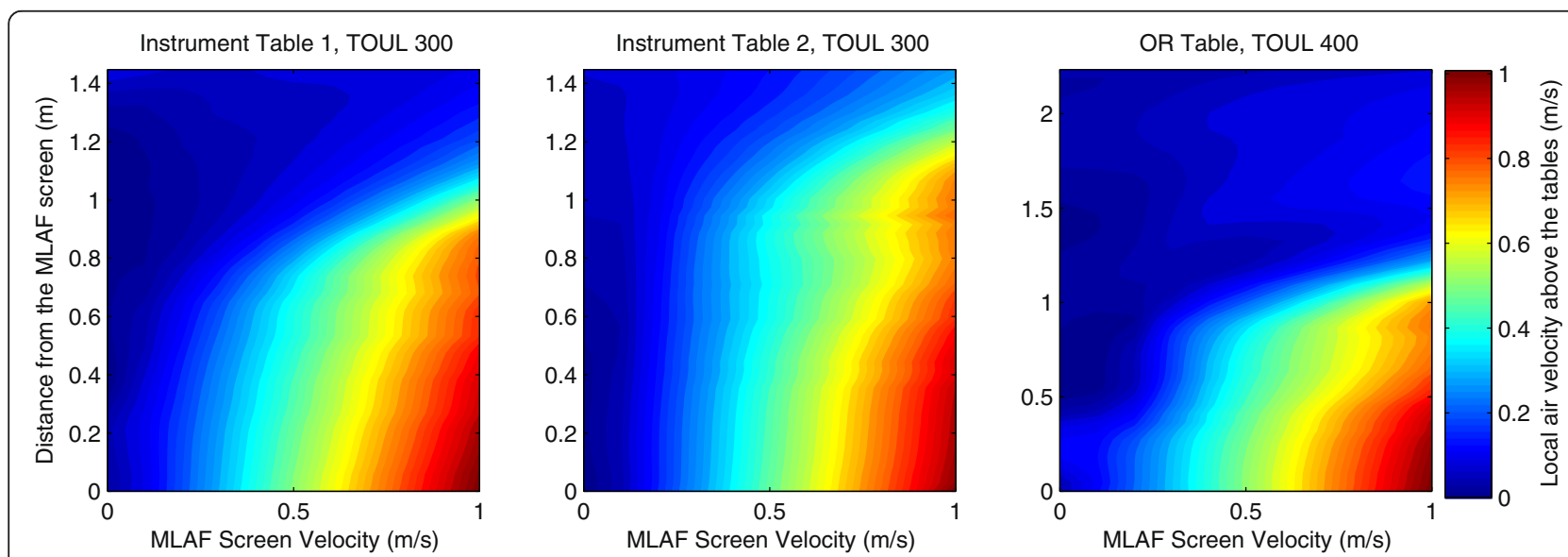

Figure 3 MLAF impact area as a function of screen-unit velocity and distance from the MLAF screen center. 
MLAF greatly depends on screen velocity. In this case, a screen velocity of $0.4 \mathrm{~m} / \mathrm{s}$ already gave good particle elimination at a distance of $1 \mathrm{~m}$ away from the screen.

\section{Discussion}

The results from the CFD simulation show that MLAF can play a marked role in reducing microbial contamination of the critical surgical zone. CFU counts showed obvious declining trends when the MLAF airflow functioned, both when analyzed as $\mathrm{CFU} / \mathrm{m}^{3}$ and $\mathrm{CFU} / \mathrm{m}^{2} / \mathrm{h}$. Surgeries in which air-borne transmission of microorganisms should be reduced to a minimum (such as hipand knee-prosthetic surgery) can be safely performed in the examined OR with the current number of staff members, even if the MLAF screen functions at the minimum velocity of $0.4 \mathrm{~m} / \mathrm{s}$. The desired count of $<10 \mathrm{CFU} / \mathrm{m}^{3}$ for infection-sensitive surgery was reached at that velocity.

Friberg et al. [15] evaluated the MLAF screen unit and found that at a distance of $1.4 \mathrm{~m}-1.6 \mathrm{~m}$ away from the screen, the bacterial count reduction rate was moderate, at approximately 80 percent. CFU simulation showed that an increase of MLAF air velocity above $0.4 \mathrm{~m} / \mathrm{s}$ did not increase the impact area. Enough washing effect to remove pathogens before they settle can be obtained at a distance of about $1 \mathrm{~m}$ away from the screen, but not further. This shows that optimal positioning of the screen unit was critical for removal efficiency. It also indicated a limitation of the usefulness of a MLAF unit.

\section{Conclusion}

The MLAF screen unit can be a suitable option when the main OR ventilation system is unable to reduce the level of microbial contamination to an acceptable level for orthopedic implant surgery. However, MLAF effect is limited to an area within $1 \mathrm{~m}$ from the screen. An increase of MALF air velocity above $0.4 \mathrm{~m} / \mathrm{s}$ does not significantly increase the impact area.

It would be valuable to perform the same simulation with and without MLAF with the staff dressed in a clothing system resulting in a source strength of $1.5 \mathrm{CFU} / \mathrm{s}-2.5 \mathrm{CFU} / \mathrm{s}$ per person $[9,24]$.

\section{Abbreviations \\ MLAF: Mobile laminar airflow; CFD: Computational fluid dynamics; OR: Operating room; SSI: Surgical-site infections; LAF: Laminar airflow; CFU: Colony-forming unit; BCP: Bacteria-carrying particles; PAS: Passive air sampling; AAS: Active air samplers; ACH: Air changes per hour.}

\section{Competing interests}

The authors declare they have no competing interests with regard to this publication.

\section{Authors' contributions}

SS: Primary author, who performed the simulation and drafted the manuscript. AN: Provided advice on the study's methodology, interpretation of the data and helped revise and refine the final manuscript. PVN: Critically edited and assisted in manuscript authorship. SH: Coordinated the study and helped to draft the manuscript. All authors read and approved the final manuscript.

\section{Author details}

${ }^{1}$ Division of Fluid and Climate Technology, School of Architecture and the Built Environment, KTH Royal Institute of Technology, Stockholm, Sweden. ${ }^{2}$ Department of Medicine, Solna (MedS), Unit of Infectious Diseases, Karolinska Institutet, Stockholm, Sweden. 'Department of Civil Engineering, Aalborg University, Aalborg, Denmark.

Received: 21 May 2014 Accepted: 18 June 2014

Published: 26 June 2014

\section{References}

1. Jenks PJ, Laurent M, McQuarry S, Watkins R: Clinical and economic burden of surgical site infection (SSI) and predicted financial consequences of elimination of SSI from an English hospital. J Hosp Infect 2014, 86:24-33.

2. Jämsen $E$, Furnes $O$, Engesaeter LB, Konttinen $Y T$, Odgaard A, Stefánsdóttir A, Lidgren L: Prevention of deep infection in joint replacement surgery. Acta Orthop 2010, 81:660-666

3. Hambraeus A: Aerobiology in the operating room-a review. $J$ Hosp Infect 1988, 11:68-76.

4. Whyte W, Vesley D, Hodgson R: Bacterial dispersion in relation to operating room clothing. J Hyg (Lond) 1976, 76:367-378.

5. Noble W, Lidwell O, Kingston D: The size distribution of airborne particles carrying micro-organisms. J Hyg 1963, 61:385-391.

6. Noble WC: Dispersal of skin microorganisms*. Br J Dermatol 1975, 93:477-485.

7. Whyte $W$, Hodgson $R$, Tinkler J: The importance of airborne bacterial contamination of wounds. J Hosp Infect 1982, 3:123-135.

8. Memarzadeh F, Manning A: Comparison of operating room ventilation systems in the protection of the surgical site. ASHRAE Trans 2002, 2:3-15.

9. Tammelin A, Ljungqvist $B$, Reinmüller $B$ : Comparison of three distinct surgical clothing systems for protection from air-borne bacteria: a prospective observational study. Patient Saf Surg 2012, 6:23.

10. Sadrizadeh S, Tammelin A, Ekolind P, Holmberg S: Influence of staff number and internal constellation on surgical site infection in an operating room. Particuology 2014, 13:42-51.

11. Lynch RJ, Englesbe MJ, Sturm L, Bitar A, Budhiraj K, Kolla S, Polyachenko Y, Duck MG, Campbell DA: Measurement of foot traffic in the operating room: implications for infection control. Am J Med Qual 2009, 24:45-52.

12. Evans RP: Current concepts for clean air and total joint arthroplasty: laminar airflow and ultraviolet radiation: a systematic review. Clin Orthop Relat Res 2011, 469:945-953.

13. Chow $T$, Yang $X Y$ : Ventilation performance in the operating theatre against airborne infection: numerical study on an ultra-clean system. J Hosp Infect 2005, 59:138-147.

14. Chow $T$, Zhang $L$, Bai $W$ : The integrated effect of medical lamp position and diffuser discharge velocity on ultra-clean ventilation performance in an operating theatre. Indoor Built Environ 2006, 15:315-331.

15. Friberga $B$, Lindgren $M$, Karlsson C, Bergström A, Friberg S: Mobile zoned/ exponential LAF screen: a new concept in ultra-clean air technology for additional operating room ventilation. J Hosp Infect 2002, 50:286-292.

16. Friberg S, Ardnor B, Lundholm R, Friberg B: The addition of a mobile ultra-clean exponential laminar airflow screen to conventional operating room ventilation reduces bacterial contamination to operating box levels. J Hosp Infect 2003, 55:92-97.

17. Nilsson K-G, Lundholm R, Friberg S: Assessment of horizontal laminar air flow instrument table for additional ultraclean space during surgery. $J$ Hosp Infect 2010, 76:243-246.

18. Pasquarella C, Sansebastiano GE, Ferretti S, Saccani E, Fanti M, Moscato U, Giannetti G, Fornia S, Cortellini P, Vitali P, Signorelli C: A mobile laminar airflow unit to reduce air bacterial contamination at surgical area in a conventionally ventilated operating theatre. J Hosp Infect 2007, 66:313-319.

19. Thore M, Burman LG: Further bacteriological evaluation of the TOUL mobile system delivering ultra-clean air over surgical patients and instruments. J Hosp Infect 2006, 63:185-192.

20. Reinmüller B: Dispersion and risk assessment of airborne contaminants in pharmaceutical clean rooms. PhD thesis. Stockholm: Royal Institute of Technology; 2001

21. Chow T-T, Yang X-Y: Performance of ventilation system in a non-standard operating room. Build Environ 2003, 38:1401-1411. 
22. Sadrizadeh S, Holmberg S: Effect of a mobile ultra-clean laminar airflow unit on particle distribution in an operating room. Particuology 2014. In Press.

23. SIS-TS 39:2012 (E): Microbiological cleanliness in the operating room - Preventingairborne contamination - Guidance and fundamental requirements. Stockholm,Sweden: Swedish Standards Institute. 2013.

24. Tammelin A, Ljungqvist B, Reinmüller B: Single-use surgical clothing system for reduction of airborne bacteria in the operating room. J Hosp Infect 2013, 84:245-247.

doi:10.1186/1754-9493-8-27

Cite this article as: Sadrizadeh et al: Does a mobile laminar airflow

screen reduce bacterial contamination in the operating room?

A numerical study using computational fluid dynamics technique.

Patient Safety in Surgery 2014 8:27.

\section{Submit your next manuscript to BioMed Central and take full advantage of:}

- Convenient online submission

- Thorough peer review

- No space constraints or color figure charges

- Immediate publication on acceptance

- Inclusion in PubMed, CAS, Scopus and Google Scholar

- Research which is freely available for redistribution 